\title{
QUANTIFYING THE HAZARD OF LARGE SUBDUCTION THRUST EARTHQUAKES IN HAWKE'S BAY
}

\author{
Martin Reyners ${ }^{1}$
}

\begin{abstract}
SUMMARY
Beneath Hawke's Bay, the interface between the subducted Pacific and overlying Australian plates lies at shallow depth - within the depth range where large subduction thrust earthquakes are expected. Determining the likely size of such earthquakes is thus a major issue in quantifying the seismic hazard of the region. Here we use recent seismological, geodetic and geologic research results to estimate the rupture dimensions, magnitude and recurrence of a large subduction thrust event. The estimated rupture zone extends $45 \mathrm{~km}$ downdip, from $15 \mathrm{~km}$ to $22 \mathrm{~km}$ depth on the plate interface, and $120 \mathrm{~km}$ along strike, from $45 \mathrm{~km}$ southwest of Napier to $10 \mathrm{~km}$ northeast of Wairoa. This equates to an $M_{w} 7.7$ earthquake. The estimated recurrence of such an event depends on the coupling coefficient (i.e. the ratio of seismic slip to total slip) at the plate interface, which is not well determined. Our preferred range for this coefficient is $0.3-0.5$, which yields a recurrence interval range of 250-400 years. Such recurrence is broadly consistent with the geological record of subsidence in the Ahuriri Lagoon near Napier in the 3500 years prior to the $M_{s} 7.8$ Hawke's Bay earthquake of 1931 .
\end{abstract}

\section{INTRODUCTION}

In the Hawke's Bay region, the Pacific and Australian plate are converging obliquely at about $42 \mathrm{~mm} / \mathrm{yr}$ (DeMets et al., 1994: Fig.1). This relative motion is accommodated by subduction of the Pacific plate and deformation of the overlying Australian plate. The subducted plate dips to the northwest, and in the Napier/Hastings region the plate interface is about $20 \mathrm{~km}$ deep (Ansell and Bannister, 1996). Interplate thrust earthquakes in the shallow part of subduction zones produce the largest and potentially the most destructive earthquakes and tsunamis worldwide, and the seismogenic zone of the plate interface which produces such large events usually lies between about 10 and $40 \mathrm{~km}$ (Hyndman et al., 1997). Thus the potential for a large thrust earthquake at the plate interface is a major issue in quantifying the seismic hazard in Hawke's Bay.

There have been no large subduction thrust events identified in the ca. 160-year historical record of seismicity in Hawke's Bay. The distribution of uplift and subsidence produced by the $M_{s} 7.8$ Hawke's Bay earthquake of 1931 February 02 indicates that this event largely involved rupture of the overlying Australian plate (Haines \& Darby, 1987). Thus we must look to inferences from seismology, geodesy and the recent geologic record to define possible rupture zones of large thrust events, and the likely recurrence of such events. Here we summarize recent research in these areas, which allows us to refine the hazard of large subduction thrust earthquakes in the region.

\section{ESTIMATING EARTHQUAKE RUPTURE DIMENSIONS AND MAGNITUDE}

To estimate the location and size of a possible large subduction thrust earthquake in Hawke's Bay, we first need to establish the location of the seismogenic zone of the plate interface. Reyners (1998) has compiled recent seismological data to map this seismogenic zone along the east coast of the North Island. His analysis has relied heavily on data from dense seismograph deployments in the Raukumara Peninsula, and southernmost North Island and northern South Island regions. The updip and downdip limits of the seismogenic zone are identified with concentrations of low-angle thrusting earthquakes near the plate interface. The location of the zone in Hawke's Bay is shown in Figure 1.

\section{Earthquake rupture width}

The updip (seaward) limit of the seismogenic zone is marked by the $15 \mathrm{~km}$-depth contour of the plate interface, in line with results in the southernmost North Island. The downdip limit of the seismogenic zone is marked by clusters of earthquakes near the plate interface with thrust mechanisms (Ansell \& Bannister, 1996). These events are interpreted as interplate slip just downdip of a locked portion of the plate interface. The seismogenic zone defined in this way by Reyners (1998) has an average downdip length of about $40 \mathrm{~km}$ in Hawke's Bay. The moderate $M_{W} 5.6$ Tikokino earthquake of 11 April 1993, which involved thrusting at the plate interface, occurred near the downdip end of this locked zone (Fig. 1). Reyners et al. (1997) have suggested that this event occurred in a region where there is a transition from unstable to conditionally stable slip. Such a transition would be expected at the downdip end of the seismogenic zone.

\footnotetext{
${ }^{1}$ Institute of Geological \& Nuclear Sciences, Lower Hutt (Member).
} 
There is some uncertainty in the location of the downdip limit of the locked portion of the plate interface. An alternative way of defining this limit in the Hawke's Bay region is to locate it at the downdip ends of the faults that ruptured through the overlying plate during the $M_{S} 7.8$ Hawke's Bay earthquake of 1931 and $M_{S} \cdot 6.9$ Wairoa earthquake of 1932 (Haines \& Darby, 1987; Fig. 1). When we do this, the seismogenic zone has an average downdip length of about $45 \mathrm{~km}$. This approach is suggested by calculations of the induced stresses caused by slip on the subduction thrust. We quantify these induced stresses in terms of changes in Coulomb failure stress, $\triangle \mathrm{CFS}$, given by

$$
\Delta \mathrm{CFS}=\Delta \tau_{\mathrm{s}}+\mu\left(\Delta \sigma_{\mathrm{n}}+\Delta \mathrm{P}\right)
$$

where $\Delta \tau_{s}$ is the induced change in shear stress, $\mu$ is the dry coefficient of friction, $\Delta \sigma_{\mathrm{n}}$ is the induced change in normal stress, and $\Delta \mathrm{P}$ is the induced change in pore pressure. The method used is explained fully in Robinson \& McGinty (2000). Changes in Coulomb failure stress that would be caused by downdip thrusting over $45 \mathrm{~km}$ width of the plate interface, extending to the downdip end of the 1931 fault plane estimated by Haines \& Darby (1987), are shown in Fig. 2. The regional stress field used in the calculation is that determined by McGinty et al. (2000) for the lower part of the overlying plate and plate interface for the southern part of the Raukumara Peninsula, and we specify an average slip of $3 \mathrm{~m}$ on the subduction thrust (see later). The changes in Coulomb failure stress shown in Fig. 2 are those expected for the fault motion which occurred in 1931, as determined by Webb \& Doser (1998); results are very similar if the fault motion estimated by Haines \& Darby (1987) is used.

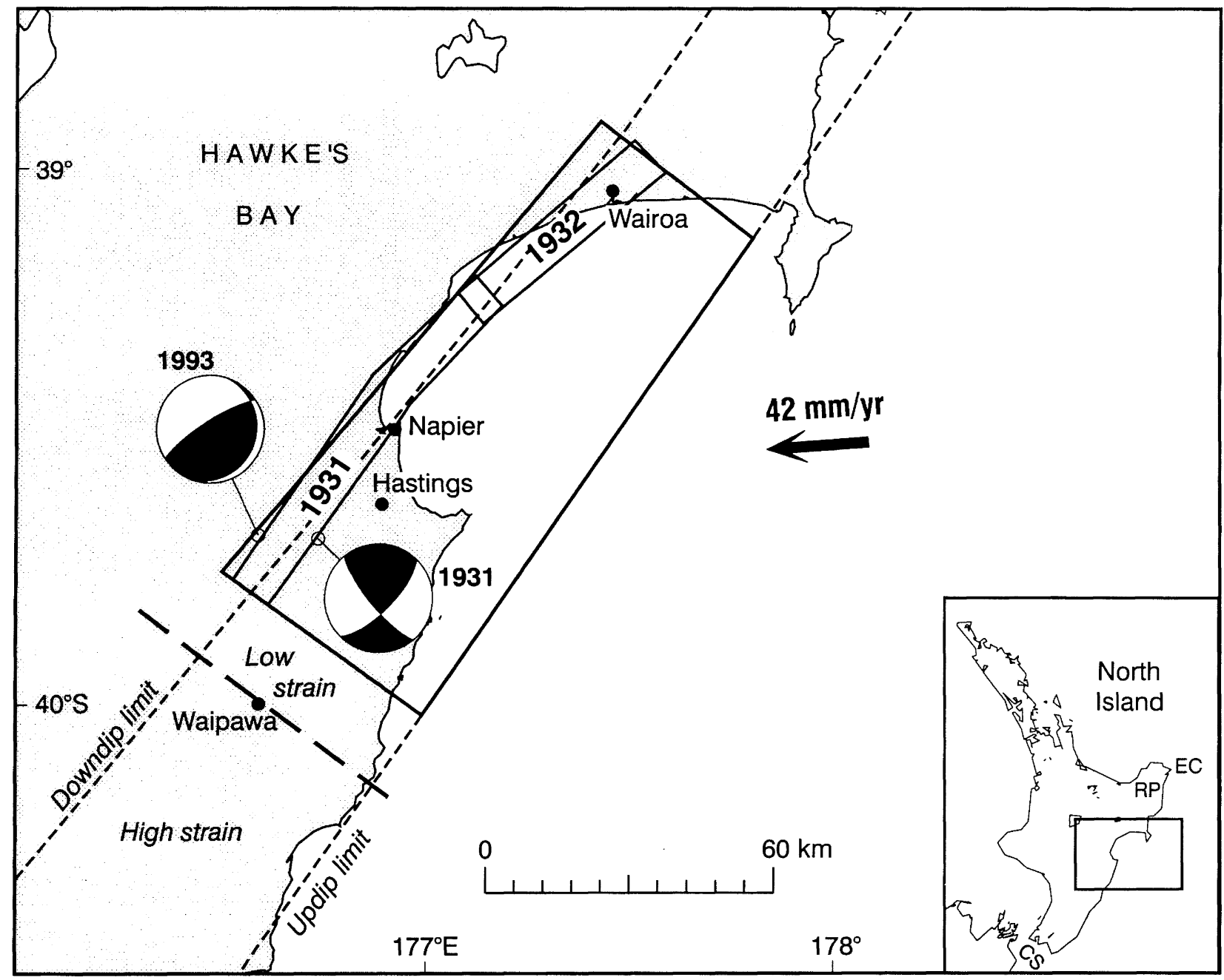

Figure 1: The inferred updip and downdip limits of the seismogenic zone of the plate interface in Hawke's Bay (short dashed lines; Reyners, 1998), together with the boundary between high and low strain regions in the overlying plate (long dashed line; Beanland et al., 1998) and vertical projections of the fault surfaces of the 1931 Hawke's Bay and 1932 Wairoa earthquakes (light-lined rectangles; Haines \& Darby, 1987). The heavy-lined rectangle indicates the portion of the seismogenic zone which might rupture in a single large subduction thrust earthquake, as estimated in this study. The locations and mechanisms of the $M_{s} 7.8$ Hawke's Bay earthquake of 1931 (Webb \& Doser, 1998) and $M_{w} 5.6$ Tikokino earthquake of 1993 (Reyners et al., 1997) are also shown; mechanisms are equal area projections of the upper focal hemisphere, with compressional quadrants shaded. The arrow shows the velocity of the Pacific plate relative to the Australian plate (DeMets et al., 1994). Abbreviations on the inset are: CS - Cook Strait; EC-East Cape; RP - Raukumara Peninsula. 
Large increases in Coulomb failure stress in the lower part of the overlying plate at the downdip end of the subduction thrust are indicated in Figure 2. Thus thrusting at the plate interface promotes slip in this part of the overlying plate, on faults similar to that which ruptured in 1931. In other words, the location of the 1931 faulting in the overlying plate is controlled by the lower limit of the seismogenic zone of the plate interface. The same is true for the 1932 Wairoa earthquake.

\section{Earthquake rupture length}

We also need to estimate how much of the seismogenic zone along strike will rupture during a possible large subduction thrust earthquake in the Hawke's Bay region. In regions where we have good control on the three-dimensional structure of both the subducted and overlying plates from earthquake arrival time tomography, we can sometimes equate possible rupture limits along strike with changes in structure (e.g. Reyners, 1998). At present there are no such data for the Hawke's Bay region. However, shallow seismic reflection and geological outcrop data indicate that a rapid reduction in strain occurs within the forearc basin north of the Waipawa River (Beanland et al., 1998; Fig. 1). As this region lies close to the southern termination of the 1931 earthquake rupture, it is plausible to associate the 1931 and 1932 ruptures in the overlying plate with a segment of the plate interface that might rupture in a single large event. Further to the southwest, the length of rupture of the Wairarapa fault in the overlying plate during the $M$ 8.1-8.2 earthquake of 1855 correlates with a distinct segment of the plate interface defined structurally (Reyners, 1998).

\section{Earthquake magnitude}

Taking the 1931 and 1932 ruptures to define a segment of the plate interface which might rupture in a single large event gives an along-strike rupture length in Hawke's Bay of about $120 \mathrm{~km}$ (Fig. 1). If this $120 \mathrm{~km}$ segment of the plate interface were to rupture in a single subduction thrust event over a downdip width of $45 \mathrm{~km}$, the relationships of Abe (1975) and Kanamori (1977) suggest an $M_{W} 7.73$ earthquake would result. This magnitude is not particularly sensitive to small changes in rupture width or length. For a length of $120 \mathrm{~km}$, a smaller width of $40 \mathrm{~km}$ gives $M_{W} 7.68$, and this magnitude rises to $M_{W} 7.77$ when the width increases to $50 \mathrm{~km}$. Similarly, for a width of $45 \mathrm{~km}$, a length of $100 \mathrm{~km}$ gives $M_{W}$ 7.65 , rising to $M_{W} 7.80$ when the length is increased to 140 $\mathrm{km}$.

\section{ESTIMATING EARTHQUAKE RECURRENCE}

How often would such a $M_{W} 7.7$ subduction thrust event recur? In the absence of a long historical record of such events, plate motion estimates provide an answer. Webb \& Anderson (1998) have shown that the oblique plate motion at the Hikurangi subduction zone is fully partitioned: that is, the plate interface accommodates very little transcurrent motion, which is instead accommodated by faults in the overlying plate. Thus, when calculating recurrence intervals for subduction thrust events we need to use the component of relative plate motion down the dip of the subducted plate. In the Hawke's Bay region, this is estimated to be $26 \mathrm{~mm} / \mathrm{yr}$ (DeMets et al., 1994). When we subtract $\sim 2 \mathrm{~mm} / \mathrm{yr}$ of permanent shortening in the overlying plate above the subduction thrust (Beanland et al., 1998), events at the plate interface need to take up about $24 \mathrm{~mm} / \mathrm{yr}$.

But how is this slip accommodated at the plate interface, both in space and time? Studies of subduction zones worldwide have demonstrated that the observed seismic moment release in subduction thrust events is often much less than that expected from plate tectonics. The ratio of the observed to expected seismic moment release rates is referred to as the coupling coefficient $(\alpha)$ of the subduction zone. Another feature of large subduction thrust earthquakes is that the coseismic slip distribution of these events is often very heterogeneous, with regions of large slip at asperities (rough spots) at the plate interface surrounded by regions of small slip (e.g. Lay and Kanamori, 1981). Pacheco et al. (1993) model such slip heterogeneity in terms of the frictional regime at the plate interface. This can be in one of three stability states: stable, conditionally stable, or unstable. Stable regions slip stably and do not accumulate strain that can be released as sudden slip in earthquakes. Thus $\alpha$ is always zero for these regions. Conditionally stable regions slip stably during the interseismic period between large events, but may be triggered to move suddenly by a rapid release of seismic moment from an adjacent unstable region. For these regions, $\alpha$ lies between 0 and 1. Unstable regions are taken to be fully coupled $(\alpha=1)$. They accumulate strain and rupture in earthquakes. As long-term strain monitoring of subduction zones improves, principally through the installation of continuously recording Global Positioning System (GPS) networks, we are learning more about the distribution of aseismic slip in time. For example, Heki et al. (1997) have demonstrated that the seismic moment released by afterslip in the year following the $M_{v i}$ 7.6 Sanriku-HaruaOki subduction thrust earthquake of 1994 was comparable to that released in the mainshock.

Thus the plate interface can be modelled as a region of heterogeneous slip, both in space and time. Asperities break with large slip during large earthquakes, while areas of reduced slip during large earthquakes tend to "catch up" through continued slip in smaller events and aseismic slip during the interseismic period. What we need to do now is estimate the proportion of aseismic slip in Hawke's Bay. Reyners (1998) has qualitatively estimated coupling at the plate interface along the Hikurangi subduction zone. In the northern South Island, both geodetic data and geologic strain rates indicate that nearly all the relative plate motion is taken up in the overlying plate. A permanently coupled plate interface is indicated, and $\alpha \approx 1$ for the plate boundary in this region. In contrast, geodetic and geologic data from the Raukumara Peninsula indicate trenchward extensional strain in the uppermost part of the overlying plate, suggesting a weakly coupled plate interface. A weak interface is also suggested by a narrow zone of high $\mathrm{P}$-wave to $\mathrm{S}$-wave velocity ratio at the plate interface, which is interpreted as due to subducted sediment in which fluid pressures are close to lithostatic (Reyners et al., 1999). In between these two regions, the seismological data indicate a gradation in coupling, with moderate to moderately weak coupling in Hawke's Bay suggested by Reyners (1998). Such a transition from a predominantly coupled interface in the south of the 
subduction zone to a predominantly uncoupled interface in the north is also indicated by GPS data (Beavan \& Haines, 1997). If $\alpha \approx 0.1$ in the northern part of the Raukumara
Peninsula, $\alpha$ in the range 0.3-0.5 would appear to be a good estimate for the Hawke's Bay region.

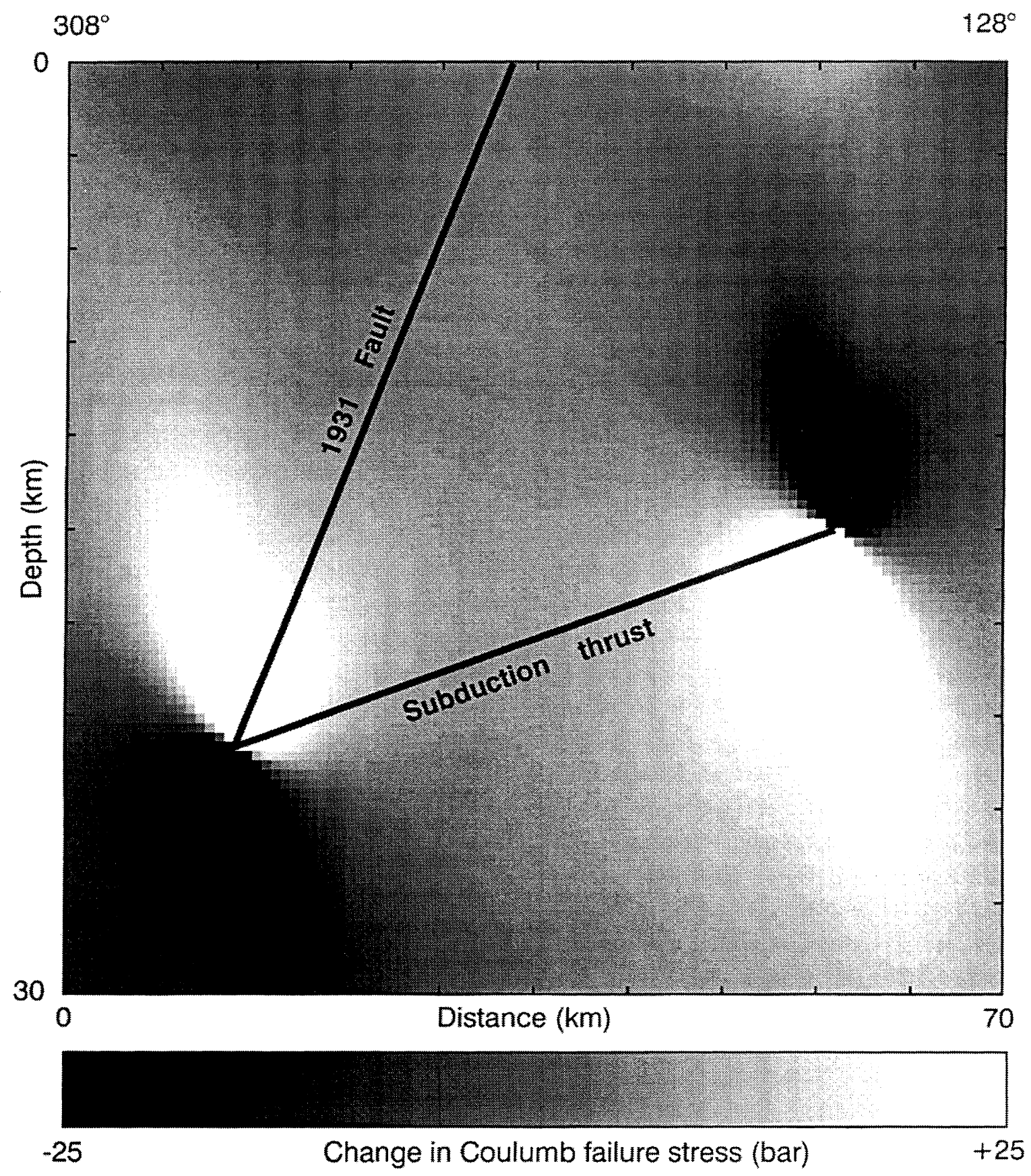

Figure 2: A depth section down the dip of the subducted plate, showing the change in Coulomb failure stress following an $M_{w} 7.7$ subduction thrust earthquake in Hawke's Bay, for fault motion similar to that which occurred during the $M_{s} 7.8$ Hawke's Bay earthquake of 1931. Slip on the subduction thrust promotes slip on the lower part of the 1931 earthquake fault. 
Given the $120 \times 45 \mathrm{~km}^{2}$ fault area estimated above, and assuming a crustal rigidity of $30 \mathrm{GPa}$, we expect an $M_{w} 7.7$ earthquake to produce an average slip of about $3 \mathrm{~m}$. If 24 $\mathrm{mm} / \mathrm{yr}$ is to be taken up at the plate interface and $\alpha=0.3$, such events would need to recur every 417 years. If $\alpha=0.5$, the corresponding recurrence interval would be 250 years.

\section{GEOLOGIC EVIDENCE FOR SUBDUCTION THRUST EARTHQUAKES}

Do we have any geologic evidence for subduction thrust events with this kind of recurrence interval? To answer this question, we first need to determine what type of tectonic signal the proposed $M_{w} 7.7$ earthquake might produce. As the proposed rupture zone does not break the surface, primary surface faulting is not expected. Rather, we need to look for surface elevation changes caused by rupture at depth. These can be calculated with an elastostatic dislocation model. Elevation changes resulting from such a model with a uniform downdip slip of $3 \mathrm{~m}$ on the rectangular equivalent of our proposed rupture zone are plotted in Figure 3. The elevation changes predicted are rather subtle, given the large $M_{w}$ of 7.7 for the earthquake. In the onshore area, a maximum subsidence of $0.6 \mathrm{~m}$ is predicted near the coast immediately north of Napier, while a maximum uplift of $0.6 \mathrm{~m}$ is predicted along the coast from Cape Kidnappers southward. It should be noted that Fig. 3 represents an average pattern of deformation, and a heterogeneous rupture will produce local variations in the uplift and subsidence pattern. For example, if $\alpha=0.3$, slip at asperities may reach $10 \mathrm{~m}$, and localized surface deformation will be commensurately larger.

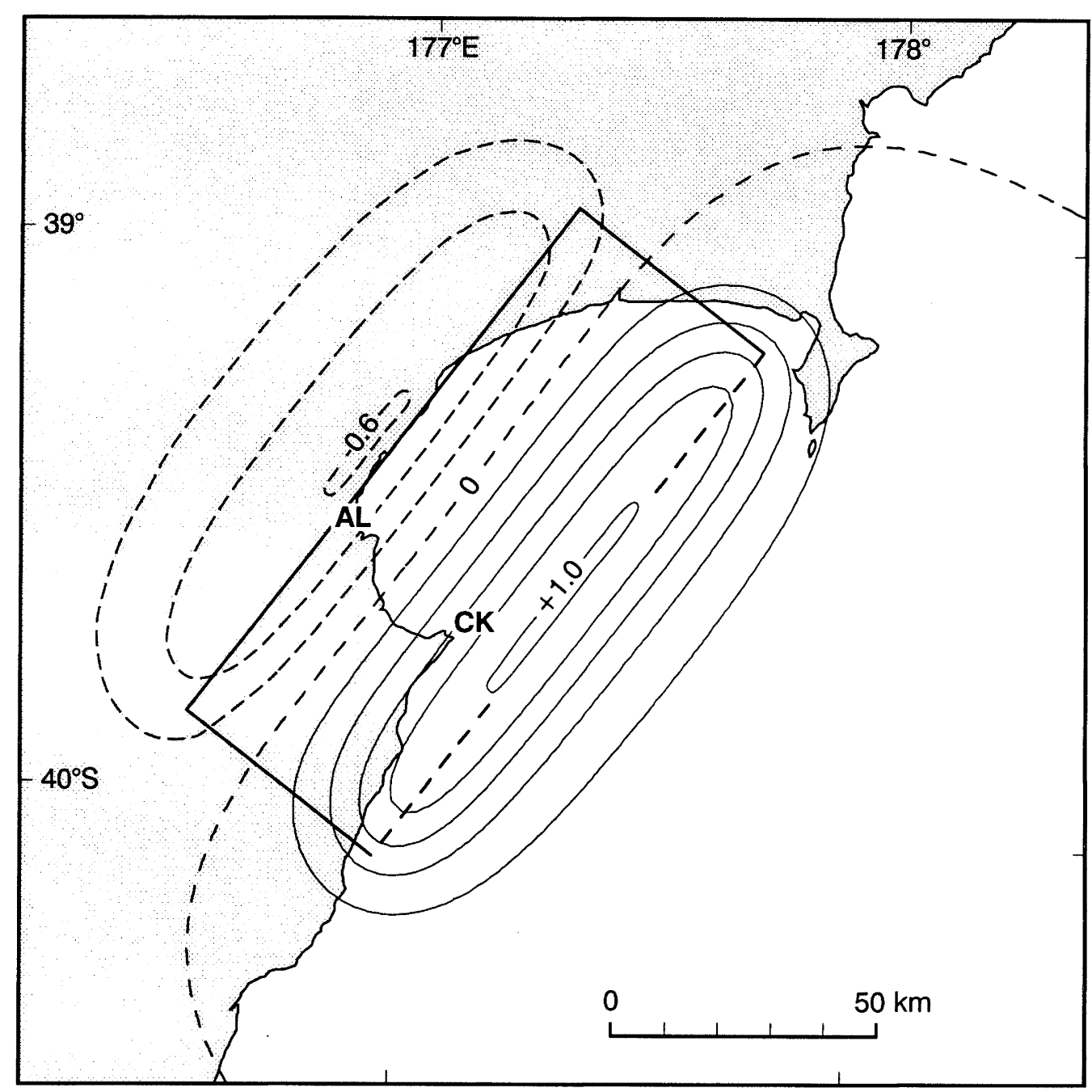

Figure 3: Elevation changes resulting from elastostatic dislocation modelling of the proposed $M_{w} 7.7$ subduction thrust earthquake in Hawke's Bay. A uniform downdip slip of $3 \mathrm{~m}$ is assumed over the rectangular fault shown. The top edge of the fault (dashed) is $15 \mathrm{~km}$ deep, while the bottom edge is $22 \mathrm{~km}$ deep. Solid contours denote uplift and dashed contours denote subsidence, and the contour interval is 0.2 m. Ahuriri Lagoon and Cape Kidnappers are identified by $A L$ and $C K$, respectively. 
Hull (1986) has used dates from submerged peat in the Ahuriri Lagoon near Napier to argue that the 1931 co-seismic uplift in this region was a reversal of a late Holocene trend of subsidence. As this lagoon lies close to the region of maximum subsidence shown in Fig. 3, this subsidence could be the result of past subduction thrust earthquakes. The last downdrop of $\sim 1 \mathrm{~m}$ occurred about 500 years ago, and rapid downdrop of $8 \mathrm{~m}$ occurred during the period $\sim 1750-3500$ years ago. The $\sim 1 \mathrm{~m}$ of downdrop at Ahuriri lagoon some 500 years ago would be consistent with the proposed model for a subduction thrust event, if slip were concentrated near the middle of the rupture. Similarly, if the total $9 \mathrm{~m}$ of subsidence in the last 3500 years identified by Hull (1986) were to have occurred in similar sized events, a recurrence interval of some 400 years is implied. This is broadly consistent with the recurrence intervals estimated above.

Tectonic uplift in the Cape Kidnappers area is also indicated by a 2300 yr-old marine terrace preserved $3.5-6.0 \mathrm{~m}$ above present mean sea level along $15 \mathrm{~km}$ of the coastline (Hull, 1987). As Hull points out, the total uplift may be the result of one or more events. The small amount of uplift and/or the rate of coastal erosion precludes preservation of most marine terraces. Indeed, most of the $2300 \mathrm{yr}$-old marine terrace has been eroded, and if another uplift does not occur soon, all evidence of that event will be removed. Also, interpretation of the marine terrace is complicated by the continued growth of the nearby late Pleistocene Kidnappers Anticline in the overlying plate. All we can really say about the tectonic uplift in the Cape Kidnappers area is that the total uplift is not inconsistent with that suggested by our proposed model of subduction thrust events and their recurrence intervals. The single event uplift of $0.6 \mathrm{~m}$ shown in Fig. 3 would need to have occurred every $230-390$ years to have produced the 3.5$6.0 \mathrm{~m}$ uplift of the $2300 \mathrm{yr}$-old marine terrace. Such recurrence intervals are again broadly consistent with those determined from seismology.

\section{DISCUSSION}

The $M_{w} 7.7$ subduction thrust earthquake in Hawke's Bay estimated in this study is smaller than previous estimates. Berryman et al. (1997) estimate an $M_{w} 8.1$ earthquake, based on a rupture zone which is $120 \mathrm{~km}$ long and $65 \mathrm{~km}$ wide, while Stirling et al. (1998) estimate $M_{w} 8.2$, based on a 145 $\mathrm{km} \times 110 \mathrm{~km}$ rupture. However, the 250-400 yr recurrence interval estimated here is shorter than those of these previous studies (2500 and $464 \mathrm{yrs}$, respectively). Thus the hazard that subduction thrust events pose to the region is still very significant. At first glance it may appear unusual that the estimated magnitude of a subduction thrust event in Hawke's Bay is now comparable to that of the $M_{s} 7.8$ Hawke's Bay earthquake of 1931. What this tells us is that the overlying plate is capable of storing a significant amount of elastic strain energy. This is a necessary condition for the occurrence of large subduction thrust events (McCaffrey, 1993).

The subduction thrust event defined here can be considered typical, in that studies of subduction zones with a long historical record have shown that large subduction thrust events tend to recur in specific segments of a plate boundary. However, sometimes two or more segments of a plate boundary rupture simultaneously, resulting in a great earthquake (e.g. Ando, 1975). If the entire $500 \mathrm{~km}$ of plate boundary between Cook Strait and East Cape were to rupture in a single event, the magnitude of such an event would be $M_{w} \sim 8.3$ (Reyners, 1998). While this should be regarded as a conservative (higher hazard) estimate for Hawke's Bay, the likelihood or recurrence of such a event is unknown at present.

While the estimates of the hazard of large subduction thrust earthquakes derived here are considered an advance on previous estimates, further work in refining them is needed. In particular, systematic mapping of the properties on the plate interface will provide constraint on the coupling coefficient. Eberhart-Phillips and Reyners (1999) have demonstrated that this is feasible through synthetic seismogram modelling of mode-converted waves from earthquakes within the subducted plate. Similarly, installation of continuously recording GPS stations should give us information on the current ratio of seismic to aseismic slip at the plate interface. Our estimate of the seismogenic zone should also be tested with thermal modelling, to see if temperatures there lie within the range found in other subduction zones (e.g. Hyndman et al., 1997).

\section{ACKNOWLEDGEMENTS}

The impetus for this paper was a request from the Hawke's Bay Regional Council for specification of a scenario subduction thrust earthquake for contingency planning purposes. The Coulomb failure stress modelling was carried out using the GNStress computer program written by Russell Robinson, and Des Darby assisted with the dislocation modelling. Hugh Cowan, Russell Robinson and Alan Hull provided constructive reviews of the paper. This research was supported in part by the New Zealand Foundation for Research, Science and Technology. Institute of Geological \& Nuclear Sciences contribution no. 1693.

\section{REFERENCES}

Abe, K. (1975). "Reliable estimation of the seismic moment of large earthquakes", Journal of physics of the Earth, 23, 381-390.

Ando, M. (1975). "Source mechanisms and tectonic significance of historical earthquakes along the Nankai trough, Japan", Tectonophysics, 27, 119-140

Ansell, J. H. and Bannister, S. C. (1996). "Shallow morphology of the subducted Pacific plate along the Hikurangi margin, New Zealand", Physics of the Earth and Planetary Interiors, 93, 3-20.

Beanland, S., Melhuish, A., Nicol, A. and Ravens, J. (1998). "Structure and deformational history of the inner forearc region, Hikurangi subduction margin, New Zealand", New Zealand Journal of Geology and Geophysics, 41, 325-342.

Beavan, J. and Haines, J. (1997). "Geodetic coupling of the Hikurangi subduction margin, New Zealand, imaged from GPS data", EOS Transactions of the American Geophysical Union, 78(46), Fall Meeting Supplement, F166. 
Berryman, K., McVerry, G. and Villamor, P. (1997). "A case study of earthquake hazard evaluation: Hawkes Bay, North Island", In: Proceedings of the New Zealand National Society for Earthquake Engineering Conference, Wairakei, New Zealand.

DeMets, C., Gordon, R. G., Argus, D. F. and Stein, S. (1994). "Effect of recent revisions to the geomagnetic reversal time scale on estimates of current plate motions", Geophysical Research Letters, 21, 2191-2194.

Eberhart-Phillips, D. and Reyners, M. (1999). "Plate interface properties in the northeast Hikurangi subduction zone, New Zealand, from converted seismic waves", Geophysical Research Letters, 26, 2565-2568.

Haines, A. J. and Darby, D. J. (1987). "Preliminary dislocation models for the 1931 Napier and 1932 Wairoa earthquakes", New Zealand Geological Survey Report EDS 114.

Heki, K., Miyazaki, S. and Tsuji, H. (1997). "Silent fault slip following an interplate thrust earthquake at the Japan Trench", Nature, 386, 595-598.

Hull, A. G. (1986). "Pre-A.D. 1931 tectonic subsidence of Ahuriri Lagoon, Napier, Hawke's Bay, New Zealand", New Zealand Journal of Geology and Geophysics, 29, 75-82.

Hull, A. G. (1987). "A late Holocene Marine terrace on the Kidnappers coast, North Island, New Zealand: some implications for shore platform development processes and uplift mechanism", Quaternary Research, 28, 183-195.

Hyndman, R. D., Yamano, M. and Oleskevich, D. A. (1997). "The seismogenic zone of subduction thrust faults", The Island Arc, 6, 244-260.

Kanamori, H. (1977). "The energy release in great earthquakes", Journal of Geophysical Research, 82, 29812987.

Lay, T. and Kanamori, H. (1981). "An asperity model of large earthquake sequences", Maurice Ewing Series, 4, 579 . 592, AGU, Washington D.C.

McCaffrey, R. (1993). "On the role of the upper plate in great subduction zone earthquakes". Journal of Geophysical Research, 98, 11953-11966.
McGinty, P., Reyners, M. and Robinson, R. (2000). "Stress directions in the shallow part of the Hikurangi subduction zone, New Zealand, from the inversion of earthquake first motions", Geophysical Journal International, in press.

Pacheco, J. F., Sykes, L. R. and Scholz, C. H. (1993). "Nature of seismic coupling along simple plate boundaries of the subduction type", Journal of Geophysical Research, 98 , 14,133-14,159.

Reyners, M. (1998). "Plate coupling and the hazard of large subduction thrust earthquakes at the Hikurangi subduction zone, New Zealand", New Zealand Journal of Geology and Geophysics 41, 343-354.

Reyners, M., McGinty, P., Ansell, J. and Ferris, B. (1997). "The Tikokino earthquake of 11 April 1993: movement at the plate interface in southern Hawke's Bay", Bulletin of the New Zealand National Society for Earthquake Engineering, 30, 242-251.

Reyners, M., Eberhart-Phillips, D. and Stuart, G. (1999). "A three-dimensional image of shallow subduction: crustal structure of the Raukumara Peninsula, New Zealand", Geophysical Journal International, 137, 873-890.

Robinson, R. and McGinty, P. J. (2000). "The enigma of the Arthur's Pass, New Zealand, earthquake, 2: the aftershock distribution and its relation to regional and induced stress fields", Journal of Geophysical Research, in press.

Stirling, M. W., Wesnousky, S. G. and Berryman, K. R. (1998). "Probabilistic seismic hazard analysis of New Zealand", New Zealand Journal of Geology and Geophysics 41, 355-375.

Webb, T. H. and Anderson, H. (1998). "Focal mechanisms of large earthquakes in the North Island of New Zealand: slip partitioning at an oblique active margin", Geophysical journal international 134, 40-86.

Webb, T. H. and Doser, D. I. (1998). "Historic seismicity of the North Island, New Zealand, and its relation to oblique subduction along the Hikurangi Margin", EOS Transactions of the American Geophysical Union, 79(45), Fall Meeting Supplement, F904. 